\title{
Effective Plant Ages for Screening for Field Resistance to Alternaria Leaf Spot (Caused by Alternaria spp.) under Natural Infection in Jerusalem artichoke (Helianthus tuberosus L.)
}

\author{
Wanalai Viriyasuthee ${ }^{1}$, Suwita Saepaisan ${ }^{2, *}$, Weerasak Saksirirat ${ }^{2}$, Mark L. Gleason ${ }^{3}$, \\ Ruey Shyang Chen ${ }^{4}$ and Sanun Jogloy ${ }^{1,5}$ (D) \\ 1 Department of Agronomy, Faculty of Agriculture, Khon Kaen University, Khon Kaen 40002, Thailand; \\ wanalai_v@hotmail.com (W.V.); sanjogloy@gmail.com (S.J.) \\ 2 Department of Entomology and Plant Pathology, Faculty of Agriculture, Khon Kaen University, \\ Khon Kaen 40002, Thailand; weerasak@kku.ac.th \\ 3 Department of Plant Pathology and Microbiology, Iowa State University, Ames, IA 50011, USA; \\ mgleason@iastate.edu \\ 4 Department of Biochemical Science and Technology, National Chiayi University, Chiayi 60004, Taiwan; \\ rschen@mail.ncyu.edu.tw \\ 5 Peanut and Jerusalem Artichoke Improvement for Functional Food Research Group, \\ Department of Agronomy, Faculty of Agriculture, Khon Kaen University, Khon Kaen 40002, Thailand \\ * Correspondence: suwitsa@kku.ac.th; Tel.: +66-43-202-209
}

Received: 18 September 2019; Accepted: 11 November 2019; Published: 14 November 2019

check for updates

\begin{abstract}
Host plant resistance has proven to be effective for controlling Alternaria leaf spot on Jerusalem artichoke (JA), but efficient screening techniques have not been developed yet. The objective of this study is to estimate the relationship between disease resistance parameters of JA as a function of plant age. Six JA varieties and three plant ages at the time of inoculation $(20,40$ and 60 days after transplanting) (DAT) are evaluated in a factorial experiment in randomized complete block design (RCBD) with four replications. Disease incidence (DI) and severity (DS) are estimated, from which area under the disease progress curve (AUDPC) was calculated. Disease parameters are positively and significantly correlated for plant ages of 40 and 60 DAT. Based on our results, screening of JA at 40 DAT for resistance to Alternaria leaf spot is recommended. Knowledge of the impact of plant age on resistance to key diseases can help breeders to accelerate breeding programs so superior genotypes can be identified before reproductive growth stages.
\end{abstract}

Keywords: Jerusalem artichoke breeding; host plant resistance; screening resistance

\section{Introduction}

JA is a tuber crop in the genus Helianthus that originated in temperate regions of North America [1]. It is a good source of inulin, a sugar which is a linear mixture of oligosaccharides and polysaccharides [2]. The tuber can be used as a raw material for health food products-particularly for diabetics because inulin is not readily absorbed by humans_-as well as in animal feed and bioethanol [3,4]. JA is currently classified as a functional food crop in tropical regions [5]. However, the production of JA in the tropic's can be subject to severe the yield loss due to drought [6], stem rot [7] and Alternaria leaf spot [8]. Alternaria leaf spot is an emerging disease of JA in these regions. The disease causes severe leaf damage, lowers photosynthesis and can reduce yield up to 80\% [9]. Alternaria leaf spot on JA appears as small yellow spots. These grow into brown spots with yellow haloes. The spots then to continue to expand and coalesce. Defoliation of infected leaves begins on mature leaves and spreads upward 
to younger leaves [8]. The initial inoculum is from plant debris and weedy host [10]. Environmental conditions conducive for infection, are temperature of $24-29^{\circ} \mathrm{C}$ [10], humidity of 80-90\% [11] and a leaf wetness period of at least 4 hours [12]. Under these conditions germ tubes penetrate the leaves and lesions are usually visible within 5-7 days after inoculation [10]. Secondary spread of the disease results from conidia by wind and irrigation. Alternaria spp. is considered polycyclic with repeating cycles of new infection [11].

Deployment of resistant varieties is an effective, economical and environmentally benign method for controlling Alternaria leaf spot in JA [8]. Screening for Alternaria leaf spot resistance has been reported in sunflower [13] and Brassica rapa [14]. Screening for Alternaria leaf spot in Helianthus can be evaluated in field and green house tests [15]. Improvement of JA resistance to Alternaria leaf spot requires effective screening techniques. The age of the plant has major influences on disease resistance. Regarding JA, correlations between seedling and adult plant resistance are found for resistance to stem rot caused by Sclerotium rolfsii $[16,17]$. Knowledge of the impact of plant age on resistance to Alternaria is needed. If resistant genotypes could be identified before reproductive growth stages this could help breeders to accelerate development of resistant varieties. The objective of this study is to examine the relationship between disease resistance parameters and plant ages in JA.

\section{Materials and Methods}

\subsection{Experimental Design}

The experiment was conducted at the Khon Kaen University Agronomy Farm, Khon Kaen, Thailand, from March to June 2017. The first trial was conducted 15 days earlier than the repeat trial. The experiment was set up using a $6 \times 3$ factorial in a RCBD-with four replications. Six JA varieties, including a resistant group (JA15, JA86 and JA116) and a susceptible group (HEL246, HEL293, and JA109) [8] were evaluated at three different plant ages (20,40, and 60 DAT). Thirty cm-diameter, $25-\mathrm{cm}$-tall pots were used with one plant per pot. The experimental unit consisted of 3 pots.

\subsection{Preparation of Potted Plants}

JA varieties were obtained from Plant Gene Resources of Canada (PGRC) Agriculture and Agri-Food Canada, Saskatoon, Saskatchewan, Canada (JA15, JA86, JA116, and JA109) and the Leibniz Institute of Plant Genetics and Crop Plant Research (IPK), Stadt, Seeland, Germany, (HEL246 and HEL293). Tubers were cut into small pieces with 2-3 active buds each and then incubated at $28 \pm 2{ }^{\circ} \mathrm{C}$ and $80 \%$ relative humidity for one week in moistened coconut coir dust to facilitate uniform germination. Germinated tuber pieces were transferred to plug trays with mixed medium (soil: charred rice husk 1:1) for one week until each seedling had two leaves. Healthy seedlings were selected for uniformity and planted in the pots. The soil was dried under the sun. The pots contained a mixture of soil and charred rice husk at a 2:1 ratio by volume and placed in the greenhouse. Seedlings were prepared to have 20-, 40-, and 60-DAT potted seedlings ready at the same time. Manual weeding was performed at 27 DAT. Chemical fertilizer (15-15-15 of $\mathrm{N}_{-} \mathrm{P}_{2} \mathrm{O}_{5}-\mathrm{K}_{2} \mathrm{O}$ at the rate of $156.3 \mathrm{~kg} \mathrm{ha}^{-1}$ ) was applied to the pots 1 month after transplanting (MAT), and irrigation was supplied as needed.

\subsection{Preparation of Experimental Field and Crop Management}

Each of the two experimental fields was plowed twice, using conventional tillage before planting. Each field was planted with two disease spreader rows in each replication. The leaf spot-susceptible cultivar, HEL293, was planted in the spreader rows to provide a secondary source of inoculum. The spreader plants were planted 60 days before transplanting the six treatment genotype to the field. The soil strip in each row of treatment pots was covered with plastic sheets to control weeds. An overhead sprinkler system was used for irrigation to create an environment favorable for the growth of spreader row plants, natural disease infection and development. Spreader rows were weeded 
manually after pots were moved to the field, and fertilizer ((15-15-15 of $\mathrm{N}-\mathrm{P}_{2} \mathrm{O}_{5}-\mathrm{K}_{2} \mathrm{O}$ at the rate of $156.3 \mathrm{~kg} \mathrm{ha}^{-1}$ ) was applied to the crops 1 MAT.

The potted plants were moved from the greenhouse to the experimental fields when plants were at 20, 40 or 60 DAT. When potted plants were transferred to each experimental field, a severe epidemic of Alternaria leaf spot was observed on plants in the spreader rows. Both fields were irrigated daily for 20 days after moving pots to the field to maintain disease-favorable conditions. The development of Alternaria leaf spot occurred through natural inoculation and infection.

\subsection{Disease Assessment}

Disease assessment was done at 2-day intervals from the date of transferring potted plants until 20 days later. Disease score was assessed according to a qualitative rating scale modified by Mayee and Datar [18] for Alternaria leaf spot as described by Viriyasuthee et al. [8].

Disease incidence (DI) was calculated as follows [19]:

$$
\text { DI }(\%)=(\text { number of infected plant/total number of plants }) \times 100
$$

Disease severity (DS) was calculated as follows [19]:

DS $(\%)=\Sigma[($ rating score $\times$ number of plants in rating $) /($ total number of sampled plants $\times$ highest rating $)] \times 100$

The area under the disease progress curve (AUDPC) was calculated for DI (AUDPC-DI) and DS (AUDPC-DS) for 20 days following by the transfer of the potted plants to the field, using the following formula [20]:

$$
\mathrm{AUDPC}=\Sigma\left[\left(\mathrm{X}_{\mathrm{i}}+\mathrm{X}_{\mathrm{i}+2}\right) / 2\right] \times\left(\mathrm{t}_{\mathrm{i}+2}-\mathrm{t}_{\mathrm{i}}\right)
$$

where $X_{i}$ is DI or DS on day $i, X_{i+2}$ is DI or DS on day $i+2$, $t_{i}$ is DI or DS on assessment day $i$ and $t_{i+2}$ are DI or DS on assessment day $\mathrm{i}+2$.

\subsection{Statistical Analysis}

Data were analyzed according to a factorial arrangement in a RCBD, and error variances between the two experimental plots were tested for homogeneity. Data sets that complied with homogeneity of error variance were subjected to the combined analysis of variance of both trials and the least significant difference (LSD) was used to compare treatment means. DI and DS at 18 days after moving pots to the fields were presented for disease data because the data showed the highest F-ratio for testing of genotypes and the lowest $\mathrm{CV}$ value. All calculations were done using the computer software STATISTIX8 software program [21]. The simple correlation was analyzed between the leaf spot-resistant traits at different plant ages.

\section{Results}

\subsection{Disease Parameters}

Concerning the combined analysis of variance, the experiments were statistically different for DI and DS. However, no difference in AUDPC was found for AUDPC-DI and AUDPC-DS (Table 1). Significant differences between varieties and plant ages were observed for DI, DS, AUDPC-DI, and AUDPC-DS. The two-way interaction between variety $\times$ plant age, experiment $\times$ variety and experiment $\times$ plant ages and three-way interactions were significant for all parameters, so the results were presented for separate experiments.

Analysis of variance for individual experiments for DI, DS, AUDPC-DI, and AUDPC-DS showed significant interaction of variety $\times$ plant age, so data were presented in a two-way tables of varieties and plant ages. 
Table 1. Mean squares of combined analysis of variance for disease incidence (\%), disease severity (\%), areas under disease progress curve of disease incidence (AUDPC-DI), areas under disease progress curve of disease severity (AUDPC-DS) of 3 plant ages of six Jerusalem artichoke varieties.

\begin{tabular}{|c|c|c|c|c|c|c|c|c|c|}
\hline \multirow{2}{*}{$\begin{array}{l}\text { Source of Variation } \\
\text { Experiment }(\mathrm{E})\end{array}$} & \multirow{2}{*}{$\begin{array}{l}\text { df } \\
1\end{array}$} & \multicolumn{2}{|c|}{ Disease Incidence $^{a}$} & \multicolumn{2}{|c|}{ Disease Severity $^{a}$} & \multicolumn{2}{|c|}{ AUDPC-DI } & \multicolumn{2}{|c|}{ AUDPC-DS } \\
\hline & & 3403 & * & 210 & $* *$ & 4082 & & 1702 & \\
\hline Rep/experiment & 6 & 347 & & 7 & & 97991 & & 3606 & \\
\hline Variety $(\mathrm{V})$ & 5 & 19292 & $* *$ & 26952 & $* *$ & 7203785 & $* *$ & 7133429 & $* *$ \\
\hline Plant age (A) & 2 & 3333 & $* *$ & 8821 & $* *$ & 3445610 & $* *$ & 2449838 & $* *$ \\
\hline $\mathrm{V} \times \mathrm{A}$ & 10 & 2000 & $* *$ & 302 & $* *$ & 867887 & $* *$ & 104968 & $* *$ \\
\hline $\mathrm{E} \times \mathrm{V}$ & 5 & 1403 & $* *$ & 454 & $* *$ & 89341 & $* *$ & 128169 & $* *$ \\
\hline $\mathrm{E} \times \mathrm{A}$ & 2 & 1944 & $* *$ & 1219 & $* *$ & 499313 & $* *$ & 547661 & $* *$ \\
\hline $\mathrm{E} \times \mathrm{V} \times \mathrm{A}$ & 10 & 1944 & $* *$ & 182 & $* *$ & 297073 & $* *$ & 57083 & $* *$ \\
\hline Pool error & 102 & 200 & & 7 & & 58601 & & 2062 & \\
\hline CV (\%) & & 16.56 & & 6.47 & & 17.76 & & 7.40 & \\
\hline
\end{tabular}

* ** Significant at $p \leq 0.05$ and $p \leq 0.01$ respectively. ${ }^{\text {a }}$ Data of disease incidence and disease severity at 18 days after inoculation in the experiment 1 and 2 .

Regarding experiment 1, the 60-DAT plants had the highest DI, DS, AUDPC-DI, and AUDPC-DS across the six varieties, followed by 40 and 20 DAT, respectively (Table 2). JA15 had the lowest DI for plant ages of 20 and 40 DAT. JA15, JA86, and JA116 had the lowest DS and AUDPC-DS for all plant ages. HEL246 had the highest DS and AUDPC-DS for all three plant ages, whereas JA109, JA86, JA116, and JA15 showed lower DS and AUDPC-DS than HEL246. HEL246, HEL293, JA109 had the highest AUDPC-DI whereas JA86, JA116, and JA15 showed low AUDPC-DI.

Concerning experiment 2, results were similar. Plants at 60 DAT had the highest DI, DS, AUDPC-DI, and AUDPC-DS across all six varieties, followed by 40 and 20 DAT, respectively (Table 3). JA15 had low DI for all plant ages whereas the other varieties had a high DI (up to 100\%). JA15, JA116, JA109, and JA86 showed low DS and AUDPC-DS at all plant ages except JA109 for AUDPC-DS, whereas HEL246 and HEL293 had the highest DS and AUDPC-DS for all plant ages. JA 15 had the lowest AUDPC-DI. The other varieties showed high AUDPC-DI for all plant ages, except for JA116 which had a low value at $20 \mathrm{DAT}$. 
Table 2. Means of disease parameters of six Jerusalem artichoke varieties at three plant ages in experiment 1.

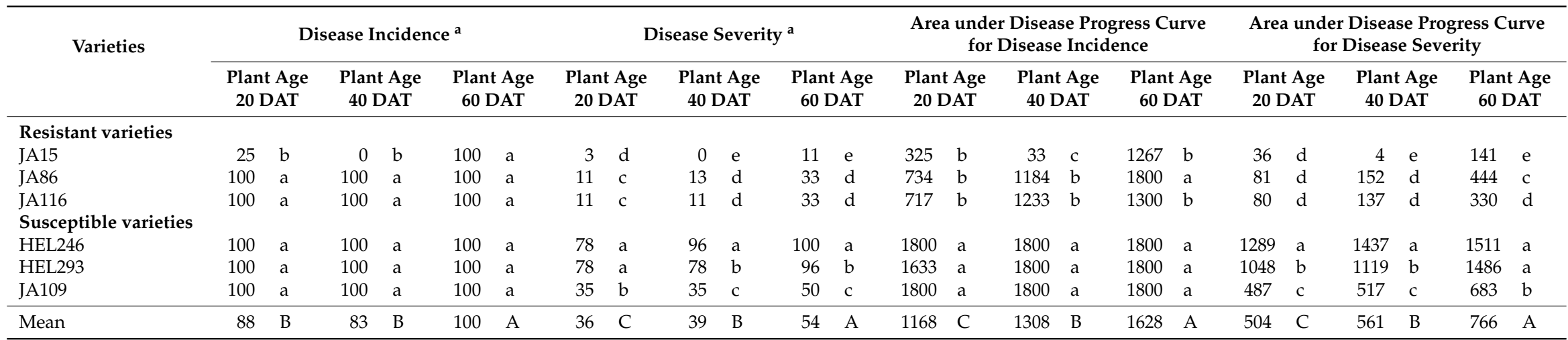

Means followed by the same capital letter in the same row or small letter in the same column do not differ significantly according to least significant difference (LSD) at $p \leq 0.05 .{ }^{a}$ Data of disease incidence and disease severity at 18 days after inoculation in experiment 1.

Table 3. Means of disease parameters of six Jerusalem artichoke varieties at three plant ages in experiment 2.

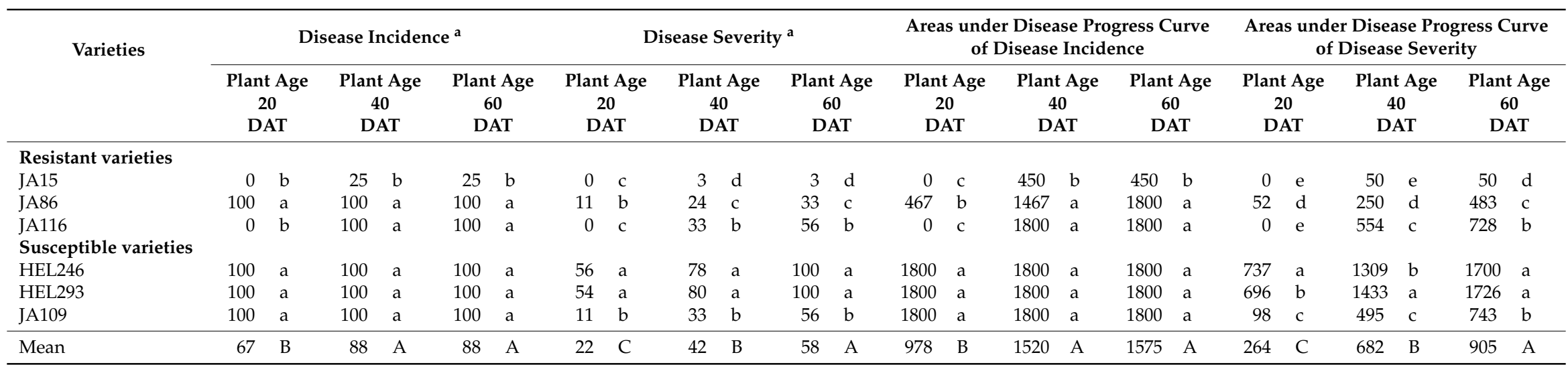

Means followed by the same capital letter in the same row or small letter in the same column do not differ significantly according to least significant difference (LSD) at $p \leq 0.05$. ${ }^{\text {a Data of }}$ disease incidence and disease severity at 18 days after inoculation in experiment 2. 


\subsection{Correlation between Different Plant Ages for Disease Parameters}

DI data from the two experiments revealed that correlations between plant ages were moderately positive and significant; 0.62 , between DI20 and DI40, 0.47 between DI20 and DI60 and 0.62 between DI40 and DI60 (Table 4). The correlation between three plant ages for DS was highly positive and significant; 0.92 between DS20 and DS40, 0.88 between DS20 and DS60, and 0.97 between DS40 and DS60. The correlations between AUDPC-DI at 20 with 40 DAT $(r=0.60)$ and 20 DAT with 60 DAT $(r=0.50)$ were moderately positive and significant, whereas the correlations between AUDPC-DI at 40 DAT with 60 DAT was significant $(r=0.80)$. The correlation between the three plant ages for AUDPC-DS was significant $(r=0.88-0.98)$.

Table 4. Correlation coefficient ( $r$ ) of disease parameters of six Jerusalem artichoke varieties and three planting ages.

\begin{tabular}{|c|c|c|c|c|c|c|c|c|}
\hline & DI20 & DI40 & DS20 & DS40 & AUDPC-DI20 & AUDPC-DI40 & AUDPC-DS20 & AUDPC-DS40 \\
\hline DI40 & $0.62 * *$ & & & & & & & \\
\hline DI60 & $0.47^{* *}$ & $0.62 * *$ & & & & & & \\
\hline DS40 & & & $0.92^{* *}$ & & & & & \\
\hline DS60 & & & $0.88^{* *}$ & $0.97 * *$ & & & & \\
\hline AUDPC-DI40 & & & & & $0.60^{* *}$ & & & \\
\hline AUDPC-DI60 & & & & & $0.50^{* *}$ & $0.80^{* *}$ & & \\
\hline AUDPC-DS40 & & & & & & & $0.88^{* *}$ & \\
\hline AUDPC-DS60 & & & & & & & $0.85^{* *}$ & $0.98^{* *}$ \\
\hline
\end{tabular}

** Significant at $p \leq 0.01$ probability level; DI20, DI40 and DI60 = disease incidence at 20, 40 and 60 DAT, respectively; DS20, DS40 and DS60 = disease severity at 20, 40 and 60 DAT, respectively; AUDPC-DI20, AUDPC-DI40 and AUDPC-DI60 = areas under disease progress curve of disease incidence at 20, 40 and 60 DAT; AUDPC-DS20, AUDPC-DS40 and AUDPC-DS60 = areas under disease progress curve of disease severity at 20, 40 and 60 DAT.

\subsection{Soil Properties and Weather Conditions}

Soil chemical and physical properties were the same for both experiments. Soil had a $\mathrm{pH}$ of 5.67, a cation exchange capacity (CEC) of $10.27 \mathrm{c} \mathrm{mol} \mathrm{(+)/kg,} \mathrm{an} \mathrm{electrical} \mathrm{conductivity} \mathrm{of} 0.081 \mathrm{ds} / \mathrm{m}$, organic matter at $0.758 \%$, total nitrogen $0.036 \%$, available phosphorus $11.85 \mathrm{mg} / \mathrm{kg}$, exchangeable potassium $53.54 \mathrm{mg} / \mathrm{kg}$, and exchangeable calcium at $270 \mathrm{mg} / \mathrm{kg}$. The soil texture was sandy loam.

Relative humidity during disease evaluation was $66-90 \%$ and $51-88 \%$ for experiment 1 and 2, respectively (Figure 1). The cumulative rainfall was 189 and $191 \mathrm{~mm}$ for experiment 1 and 2, respectively. The maximum temperature during disease evaluation ranged from $28.3-38.2{ }^{\circ} \mathrm{C}$ and $28.3-36.7^{\circ} \mathrm{C}$ for experiment 1 and 2 , respectively. The minimum temperature ranged from $21.6-26.7^{\circ} \mathrm{C}$ for both experiment. Generally, the weather for both experiments was similar.

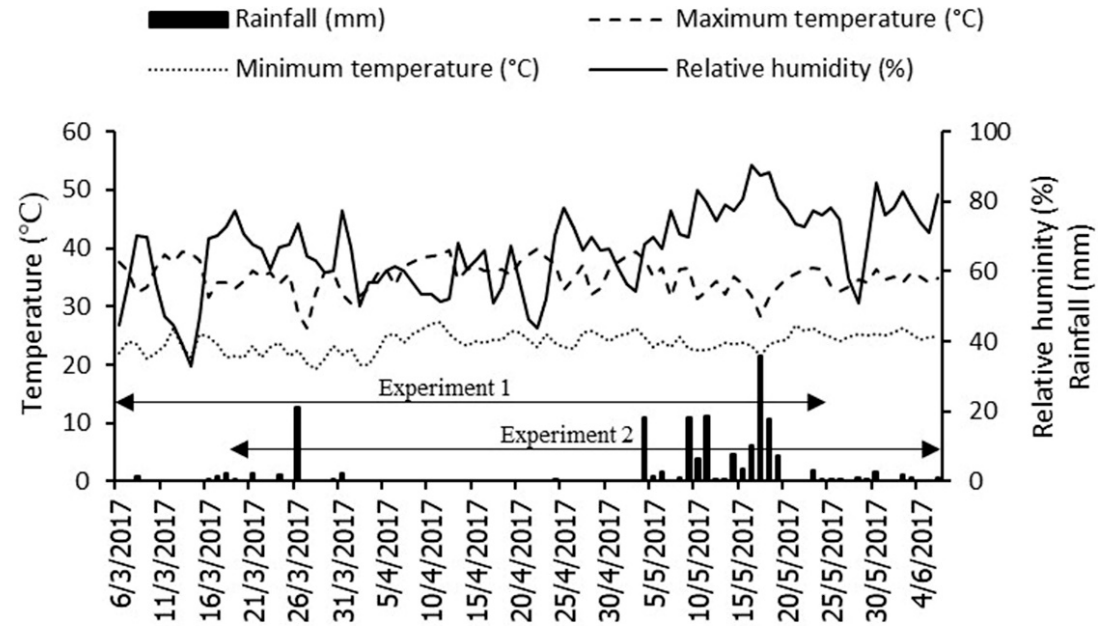

Figure 1. Rainfall, relative humidity, maximum and minimum temperature for the two experiments conducted during 6 March-7 June 2017. Experiment 1 was conducted during 6 March-24 May 2017, and experiment 2 was conducted during 20 March-7 June 2017. 


\section{Discussion}

Information about the relationship of leaf spot resistance to different ages of JA plants has not been reported in the literature. However, there were previous studies that examined the relationship between plant age and JA resistance to stem rot caused by Sclerotium rolfsii [16]. Viriyasuthee et al. [8] observed that field screening JA for resistance to Alternaria leaf spot could be conducted during the late bloom state (75-80 DAT). The beginning of the anthesis stage is approximately 60 DAT or 1725 degree day ${ }^{\circ} \mathrm{C}$ [22]. Waiting to screen for resistance until the bloom stage is not convenient nor efficient for breeders who need to decide before blooming which accessions have potential in crosses. The present results showed that the correlation of DS, AUDPC-DI, and AUDPC-DS between 40 and 60 DAT were significant, $r=0.97,0.80$, and 0.98 , respectively (Table 4). Thus, screening for resistance to Alternaria leaf spot at 40 and 60 DAT should produce similar results. The correlation between DI and AUDPC-DI between 20 and 60 DAT was intermediate and significant (Table 4). Screening for resistance beginning at 40 DAT and continuing for 18 days (58 DAT) would be more effective than starting at 20 DAT and continuing until 38 DAT, or starting at 60 DAT and evaluating until 78 DAT. Referring to the previous study [8] that suggested 75-80 DAT as a favorable time to assess the resistance of breeding lines, the present study suggests that the preferred evaluation window is 40-58 DAT. This target period is sufficient to discern genetic resistance to Alternaria leaf spot and allows time to select resistant accessions before making crosses. High positive correlation between the adult stage and the seedling stage have also been reported for resistance to tan spot (Pyrenophora triticirepentis) in wheat [23] and for resistance to Ascochyta rabiei in chickpea [24].

Disease pressure changes over seasons, however, a previous report [8] indicated that the genotype $\times$ season interactions for disease parameters including disease severity, area under disease progress curve of disease incidence, and area under disease progress curve of disease severity were 2-4 times lower in magnitude of variation than those of genotype main effect. Results from the present study indicated that the genotypes could be consistently grouped into resistant and susceptible groups. Previous reports indicated that the optimum conditions for Alternaria infection were 24-29 ${ }^{\circ} \mathrm{C}$ [10], $80-90 \%$ relative humidity [11], and leaf wetness for 4 hours [12]. Temperatures during the present study were higher than the reported optimum, however high disease incidence, and severity, especially in the susceptible genotype, were found (Tables 2 and 3).

JA is a cross-pollinated crop that is vegetatively propagated using tubers [5]. Recurrent selection is widely used for developing improved varieties of cross-pollinated crops [25]. This breeding method includes evaluation and selection of plants from a base population, then making crosses among selected plants and harvesting seed to form a new population. Results from the present study, demonstrated that disease resistance among accessions of JA can be discerned reliably before flowering. Using the 40-58 DAT window for evaluation, breeders can, therefore, complete a breeding cycle within a year, especially in tropical areas such as Thailand. The knowledge of different plant ages for screening for resistance should help breeders to accelerate breeding programs since superior varieties can be identified before reproductive growth stages. These findings are consistent with the preliminary results from two runs of experiment within a one-year study, which may not show sufficiently firm outcomes. Future studies should be replete for more than one environments.

\section{Conclusions}

To conclude, the correlations of DS, AUDPC-DI, and AUDPC-DS between 40 and 60 DAT were highly positive and significant. Therefore, screening for resistance to Alternaria leaf spot of JA at 40 and 60 DAT should yield similar findings. During application, for an accelerated breeding program, screening at 40 day old plants would be recommended for breeders intending to select for resistance to this important fungal disease, since they can select resistant plants and generate crosses during a single cropping year. 
Author Contributions: Conceptualization, S.S., W.S. and S.J.; Data curation, W.V.; Formal analysis, W.V.; Investigation, W.V.; Methodology, S.S., W.S. and S.J.; Resources, S.S., M.L.G., R.S.C.; Supervision, S.S., S.J.; Writing—original draft, W.V.; Writing—review and editing, W.V., S.S., M.L.G. and S.J.

Funding: This research was funded by the Royal Golden Jubilee Ph.D. Program (grant no. PHD/0066/2556), the Thailand Research Fund through the Senior Scholar Project of Professor Sanun Jogloy (RTA6180002) and Peanut and Jerusalem Artichoke improvement for Functional Food Project, Khon Kaen University.

Acknowledgments: The Thailand Research Fund through the Senior Scholar Project of Professor Sanun Jogloy (RTA6180002) and Peanut and Jerusalem Artichoke improvement for Functional Food Project, Khon Kaen University. The Leibniz Institute of Plant Genetics and Crop Plant Research (IPK), Stadt, Seeland, Germany, and the Plant Gene Resources of Canada (PGRC) Agriculture and Agri-Food Canada, Saskatoon, Saskatchewan, Canada are acknowledged for their donation of Jerusalem artichoke germplasm and C.C. Holbrook for English editing of this manuscript.

Conflicts of Interest: The authors declare no conflict of interest.

\section{References}

1. Jerusalem Artichoke Alternative Field Crops Manual. Available online: http://www.hort.purdue.edu/ newcrop/afcm/jerusart.html (accessed on 2 April 2018).

2. Gunnarsson, I.B.; Svensson, S.E.; Johansson, E.; Karakashev, D.; Angelidaki, I. Potential of Jerusalem artichoke (Helianthus tuberosus L.) as a biorefinery crop. Ind. Crops Prod. 2014, 56, 231-240. [CrossRef]

3. Baldini, M.; Danuso, F.; Monti, A.; Amaaducci, M.T.; Stevanato, P.; De Mastro, G. Chicory and Jerusalem artichoke productivity in different areas of Italy, in relation to water availability and time of harvest. Ital. J. Agron. 2006, 6, 126-132. [CrossRef]

4. Baldini, M.; Danuso, F.; Rocca, A.; Bulfoni, E.; Monti, A.; De Mastro, G. Jerusalem artichoke (Helianthus tuberosus L.) productivity in different Italian growing areas: A modeling approach. Ital. J. Agron. 2011, 2, 291-307. [CrossRef]

5. Kays, S.J.; Nottingham, S.F. Biology and Chemistry of Jerusalem Artichoke Helianthus Tuberosus L.; CRC Press Taylor \& Francis: Boca Raton, FL, USA, 2008.

6. Ruttanaprasert, R.; Banterng, P.; Jogloy, S.; Vorasoot, N.; Kesmala, T.; Kanwar, R.S.; Holbrook, C.C.; Patanothai, A. Genotypic variability for tuber yield, biomass and drought tolerance in Jerusalem artichoke germplasm. Turk. J. Agric. For. 2014, 38, 570-580. [CrossRef]

7. Sennoi, R.; Jogloy, S.; Saksirirat, W.; Kesmala, T.; Patanothai, A. Genotypic variation of resistance to southern stem rot of Jerusalem artichoke caused by Sclerotium rolfsii. EUPHYTICA 2013, 190, 415-424. [CrossRef]

8. Viriyasuthee, W.; Saksirirat, W.; Saepaisan, S.; Gleason, M.L.; Jogloy, S. Variability of Alternaria leaf spot in Jerusalem artichoke (Helianthus tuberosus L.) accessions grown in a humid tropical region. Agronomy 2019, 9, 268. [CrossRef]

9. Dudhe, M.Y.; Bharsakle, S.S. Screening of germplasm line for resistance to Alterneria blight and necrosis disease in sunflower. Crop Prot. Prod. 2005, 2, 84-87.

10. Early Blight of Potato and Tomato. Available online: https://www.apsnet.org/edcenter/disandpath/fungalasco/ pdlessons/Pages/PotatoTomato.aspx (accessed on 16 July 2019).

11. Gopalakrishnan, C.; Manivannan, N.; Vindhiyavarman, P.; Thiyagarajan, K. Evaluation and identification of Alternaria leaf spot resistant sunflower genotypes. EJPB 2010, 1, 177-181.

12. Vloutoglou, I.; Kalogerakis, S.N. Effects of inoculum concentration, wetness duration and plant age on development of early blight (Alternaria solani) and on shedding of leaves in tomato plants. Plant Pathol. 2000, 49, 339-345. [CrossRef]

13. Morris, J.B.; Yang, S.M.; Wilson, L. Reaction of Helianthus species to Alternaria helionthi. Plant Dis. 1983, 67, 539-540. [CrossRef]

14. Doullah, M.A.U.; Meah, M.B.; Okazaki, K. Development of an effective screening method for partial resistance to Alternaria brassicicola (dark leaf spot) in Brassica rapa. Eur. J. Plant Pathol. 2006, 116, 33-43. [CrossRef]

15. Lipps, P.E.; Herr, L.J. Reactions of Helianthus annuus and H. tuberosus plant introductions to Alternaria helianthi. Plant Dis. 1986, 70, 831-835. [CrossRef]

16. Sennoi, R.; Jogloy, S.; Saksirirat, W.; Banterng, P.; Kesmala, T.; Patanothai, A. Evaluation of seedling and adult plant stages resistance Sclerotium rolfsii Sacc. in Jerusalem artichoke (Helianthus tuberosus L.). SABRAO J. Breed. Genet. 2013, 45, 324-331. 
17. Junsopa, C.; Jogloy, S.; Saksirirat, W.; Songsri, P.; Kesmala, T.; Shew, B.B. Association of seedling and adult plant resistance to Sclerotium rolfsii in Jerusalem artichoke (Helianthus tuberosus L.) under field conditions. Eur. J. Plant Pathol. 2018, 151, 251-255. [CrossRef]

18. Mayee, C.D.; Datar, V.V. Phytopathometry Tech Bull-1; Marathwad Agricultural University: Parabhani, India, 1986.

19. Anfok, G.H. Benzo-(1,2,3)-thiadiazole-7-carbothioic acid S-methyl ester induces systemic resistance in tomato (Lycopersicon esculentum. Mill cv. Vollendung) to cucumber mosaic virus. Crop Prot. 2000, 19, 401-405. [CrossRef]

20. Ojiambo, P.S.; Narla, R.D.; Ayiecho, P.O.; Nyabundi, J.O. Effect of infection level of sesame (Sesamum indicum L.) seed by Alternaria sesame on severity of Alternaria leaf spot. Tare 1998, 1, 125-130.

21. Statistix8. Analytical Software User's Manual; Analytical Software: Tallahassee, FL, USA, 2003.

22. Paungbut, D.; Jogloy, S.; Vorasoot, N.; Patanothai, A. Growth and phenology of Jerusalem artichoke (Helianthus tuberosus L.). Pak. J. Bot. 2015, 47, 2207-2214.

23. Tadesse, W.; Reents, H.J.; Hsam, S.L.K.; Zeller, F.J. Relationship of seedling and adult plant resistance and evaluation of wheat germplasm against tan spot (Pyrenophora tritici-repentis). Genet. Resour. Crop Evol. 2011, 58, 339-346. [CrossRef]

24. Chongo, G.; Gossen, B.G. Effect of plant age on resistance to Ascochyta rabiei in chickpea. Can. J. Plant Pathol. 2001, 23, 358-363. [CrossRef]

25. Fehr, W.R. Principles of Cultivar Development; Macmillan Publishing Company: New York, NY, USA, 1987.

(C) 2019 by the authors. Licensee MDPI, Basel, Switzerland. This article is an open access article distributed under the terms and conditions of the Creative Commons Attribution (CC BY) license (http://creativecommons.org/licenses/by/4.0/). 